\title{
Hexagonal $\mathrm{Ti}_{2} \mathrm{~B}_{2}$ monolayer: A Promising Anode Material Offering High Rate Capability for Li-Ion and Na-Ion Batteries
}

Tao $\mathrm{Bo}^{\mathrm{a}, \mathrm{b}}$, Peng-Fei Liu ${ }^{\mathrm{a}, \mathrm{b}}$, Juping $\mathrm{Xu}^{\mathrm{a}, \mathrm{b}}$, Junrong Zhang ${ }^{\mathrm{a}, \mathrm{b}}$, Fangwei Wang ${ }^{\mathrm{a}, \mathrm{b}, \mathrm{c}}$, Bao-Tian Wang ${ }^{\mathrm{a}, \mathrm{b}, *}$

a Institute of High Energy Physics, Chinese Academy of Science (CAS), Beijing 100049, China

${ }^{\mathrm{b}}$ Dongguan Neutron Science Center, Dongguan 523803, China

c Beijing National Laboratory for Condensed Matter Physics, Institute of Physics, Chinese Academy of Sciences, Beijing 100080, China

E-mail:wangbt@ihep.ac.cn

\begin{abstract}
:
Combining first-principles density functional method and crystal structure prediction techniques, we report a series of hexagonal two-dimensional (2D) transition metal borides (TMBs) including $\mathrm{Sc}_{2} \mathrm{~B}_{2}, \mathrm{Ti}_{2} \mathrm{~B}_{2}, \mathrm{~V}_{2} \mathrm{~B}_{2}, \mathrm{Cr}_{2} \mathrm{~B}_{2}, \mathrm{Y}_{2} \mathrm{~B}_{2}, \mathrm{Zr}_{2} \mathrm{~B}_{2}$, and $\mathrm{Mo}_{2} \mathrm{~B}_{2}$. Their dynamic and thermal stabilities are testified by phonon and molecular dynamics simulations. We investigate the potential of $2 \mathrm{D} \mathrm{Ti}_{2} \mathrm{~B}_{2}$ monolayer as the anode material for Li-ion batteries (LIBs) and Na-ion batteries (NIBs). The $\mathrm{Ti}_{2} \mathrm{~B}_{2}$ monolayer possesses high theoretical specific capacities of 456 and 1027 $\mathrm{mAhg}^{-1}$ for $\mathrm{Li}$ and $\mathrm{Na}$, respectively. The very high $\mathrm{Li} / \mathrm{Na}$ diffusivity with ultralow energy barrier of 0.017/0.008 eV indicates an excellent charge-discharge capability. In addition, the good electronic conductivity during the whole lithiation process is found by electronic structure calculations. The very small change in volume after the adsorption of one, two, and three layers of $\mathrm{Li}$ and $\mathrm{Na}$ ions indicates that the $\mathrm{Ti}_{2} \mathrm{~B}_{2}$ monolayer is robust. These results highlight the suitability of $\mathrm{Ti}_{2} \mathrm{~B}_{2}$ monolayer as well as the other 2D TMBs as excellent anode materials for both LIBs and NIBs.
\end{abstract}

Keywords: $\mathrm{Ti}_{2} \mathrm{~B}_{2}$; Specific capacity; Diffusion barrier; Li-ion batteries; Na-ion batteries; First-principles 


\section{Introduction}

Research on advanced energy storage technology is significant for the development of modern society [1]. Rechargeable lithium-ion batteries (LIBs), one of the widely studied clean energy-storage technologies, have attracted increasing attention due to the combination of outstanding reversible capacity, high power density, superior energy efficiency, long cycle life, and portability [2-9]. Currently, LIBs are widely applied in portable electronics, electric vehicles, and electricity grid systems $[10,11]$. In addition to LIBs, an alternative option is the rechargeable Na-ion batteries (NIBs), which have been found promising and can be a good candidate to replace LIBs in the future because sodium is more abundant and cheaper than lithium [12-16]. The capability of LIBs and NIBs is highly dependent on the performances of their electrode materials $[17,18]$. Nowadays, graphite is commercially used as anode material for LIBs because of its high Coulombic efficiency, relatively good cycling stability, and low cost $[19,20]$, but the relatively low theoretical specific capacity $(372 \mathrm{mAh} / \mathrm{g})$ and poor rate capability restricts its further application [21]. In addition, graphite cannot be used in NIBs, because the Na-C interaction is found to be too weak to contribute to the necessary Coulomb interactions [22]. Therefore, seeking for new anode materials to further improve the performance of LIBs and NIBs is urgently needed [23-25].

2D materials $[26,27]$ are of special interest as anode materials for LIBs and NIBs because of their high surface area, remarkably high electron mobility and superior mechanical properties [28]. In recent years, many 2D materials have been investigated as anode materials and great success has been obtained [29-44]. Graphene represents the first example of a 2D electrode material for LIBs [45, 46]. Since then, novel 2D materials including $\mathrm{MoS}_{2}$ [47], $\mathrm{VS}_{2}$ [48], silicene [49], phosphorene [50-52], borophene [29, 53], borophane [35], boron phosphide [36], $\mathrm{Mo}_{2} \mathrm{C}$ [38], and so on have been investigated as anode materials for LIBs or NIBs. In addition, 2D transition metal carbides or nitrides, called MXenes [54, 55], have also attracted great interest in this field [30-32]. The MXenes can be synthesized by selective etching of A atoms 
from MAX phases with hydrofluoric acid (HF) at room temperature $[54,55]$ and the advantage of easy fabrication offers an intrinsic potential for their practical applications [54, 56-59]. Although many 2D materials have been confirmed theoretically as potential electrode materials, the search for LIBs and NIBs with better performance is still necessary and significant. Very recently, Guo et al [60]. have investigated new 2D TMBs such as $\mathrm{Fe}_{2} \mathrm{~B}_{2}$ and $\mathrm{Mo}_{2} \mathrm{~B}_{2}$ for LIBs. As far as we know, this is the first time that 2D TMBs have been investigated as LIBs. These 2D TMBs belong to orthorhombic system and can be obtained from layered orthorhombic TMBs that possess highly structural similarity to the MAX phases. In addition to these orthogonal structures, there are also a family of layered TMBs which belong to hexagonal crystal system with the formula of $\mathrm{TMB}_{2}$. These layered TMBs contain graphene-like honeycomb boron layers and can be transformed into 2D "sandwich" structures which consist of two boron honeycomb sheets and an intermediate hexagonal plane of TM atom (B-TM-B) $[61,62]$. However, because the outermost sheets of MXenes are composed of metallic atoms, we are interested in whether the hexagonal TMBs can also be transformed into 2D structure consisting of an intermediate boron honeycomb and two outer hexagonal planes of TM atoms (TM-B-TM). Besides, it is our great interest to investigate the potential applications of these 2D materials as LIBs and NIBs.

In this work, we first report a series of $2 \mathrm{D}$ TMBs including $\mathrm{Sc}_{2} \mathrm{~B}_{2}, \mathrm{Ti}_{2} \mathrm{~B}_{2}, \mathrm{~V}_{2} \mathrm{~B}_{2}$, $\mathrm{Cr}_{2} \mathrm{~B}_{2}, \mathrm{Y}_{2} \mathrm{~B}_{2}, \mathrm{Zr}_{2} \mathrm{~B}_{2}$, and $\mathrm{Mo}_{2} \mathrm{~B}_{2}$. This monolayer $\mathrm{TM}_{2} \mathrm{~B}_{2}$ belongs to the space group of $\mathrm{P} 6 / \mathrm{mmm}$ with 4 atoms in a hexagonal unit cell, which is identified consisting of an intermediate boron honeycomb sheet sandwiched in between two hexagonal planes of TM atoms. These 2D TMBs can be produced from their bulk phase which is a family of layered TMBs of hexagonal crystal system with the formula of $\mathrm{TMB}_{2}$. Furthermore, we choose $\mathrm{Ti}_{2} \mathrm{~B}_{2}$ as the representative and investigate its performance as an anode material for LIBs and NIBs by performing first-principles calculations. Our results illustrate that $\mathrm{Ti}_{2} \mathrm{~B}_{2}$ monolayer is a promising electrode material for LIBs and NIBs. This fact is encouraging and indicates that our predicted series of 2D TMBs could be 
promising candidates for the next-generation portable batteries.

\section{Computational method}

The particle-swarm optimization (PSO) scheme, as implemented in the CALYPSO code [63-65], is employed to search for low energy $2 \mathrm{D} \mathrm{Ti}_{2} \mathrm{~B}_{2}$ structures. The underlying energy calculations and structure optimizations are performed by using the plane-wave-based density-functional theory (DFT) method as implemented in the Vienna ab-initio Simulation Package (VASP) [66-68]. The computational details of the PSO and DFT methods are illustrated in the Supporting Information. The adsorption energy of lithium and sodium atoms on the $\mathrm{Ti}_{2} \mathrm{~B}_{2}$ monolayer is obtained from:

$$
E_{\mathrm{ad}}=\left(E_{T_{i_{2} B_{2} M}}-E_{T_{i_{2} B_{2}}}-n E_{M}\right) / n(M=L i, N a)
$$

where $E_{T i_{2} B_{2} M}$ and $E_{T i_{2} B_{2}}$ represent the total energies of the metal-ion adsorbed monolayer system and the isolated monolayer, respectively, $E_{M}$ represents the total energy of per atom for the bulk metal. The charge density difference $\Delta \rho$ are calculated based on the following equation:

$$
\Delta \rho=\rho_{T i_{2} B_{2} M}-\rho_{T i_{2} B_{2}}-\rho_{M}(M=L i, N a)
$$

where $\rho_{T_{i_{2} B_{2} M}}, \rho_{T_{i_{2} B_{2}}}$, and $\rho_{M}$ are the total charge of the $\mathrm{Li} / \mathrm{Na}$ adsorbed system, the $\mathrm{Ti}_{2} \mathrm{~B}_{2}$ monolayer, and the $\mathrm{Li} / \mathrm{Na}$ atom, respectively. The open circuit voltage can be obtained using a well-established approach [69] according to the following formula:

$$
V=-\left(E_{T_{2} B_{2} M}-E_{T_{i_{2} B_{2}}}-n E_{M}\right) / n(M=L i, N a)
$$

To assess the adsorption stability of $\mathrm{Li} / \mathrm{Na}$ layer on the $\mathrm{Ti}_{2} \mathrm{~B}_{2}$ monolayer, the average adsorption energies for each $\mathrm{Li} / \mathrm{Na}$ layer are calculated according to the following equation:

$$
E_{\text {ave }}=\left(E_{T i_{2} B_{2} M_{n}}-E_{T i_{2} B_{2} M_{(n-1)}}-m E_{M}\right) / m(M=L i, N a)
$$

where $E_{T_{2} B_{2} M_{n}}$ and $E_{T_{2} B_{2} M_{(n-1)}}$ are the total energies of $2 \mathrm{D} \mathrm{Ti}_{2} \mathrm{~B}_{2}$ with $\mathrm{n}$ and $(\mathrm{n}-1)$ adsorbed $\mathrm{Li} / \mathrm{Na}$ layers, $E_{M}$ stands for the total energy of per atom for the bulk metal. The number $\mathrm{m}$ represents $\mathrm{m}$ adsorbed $\mathrm{Li} / \mathrm{Na}$ atoms in each layer (for a $2 \times 2$ supercell 
on both sides). The theoretical capacity can be obtained from:

$C_{A}=c z F / M_{T_{2} B_{2}}$

where $c$ is the number of adsorbed $\mathrm{Li} / \mathrm{Na}$ ions, $z$ is the valence number of $\mathrm{Li} / \mathrm{Na}, F$ is Faraday constant $(26801 \mathrm{mAh} / \mathrm{mol})$, and $M_{T_{2} B_{2}}$ is the molar weight of $\mathrm{Ti}_{2} \mathrm{~B}_{2}$.

\section{Results and Discussion}

\subsection{D TM $\mathrm{TB}_{2}$ and Bulk TMB2.}

(a)
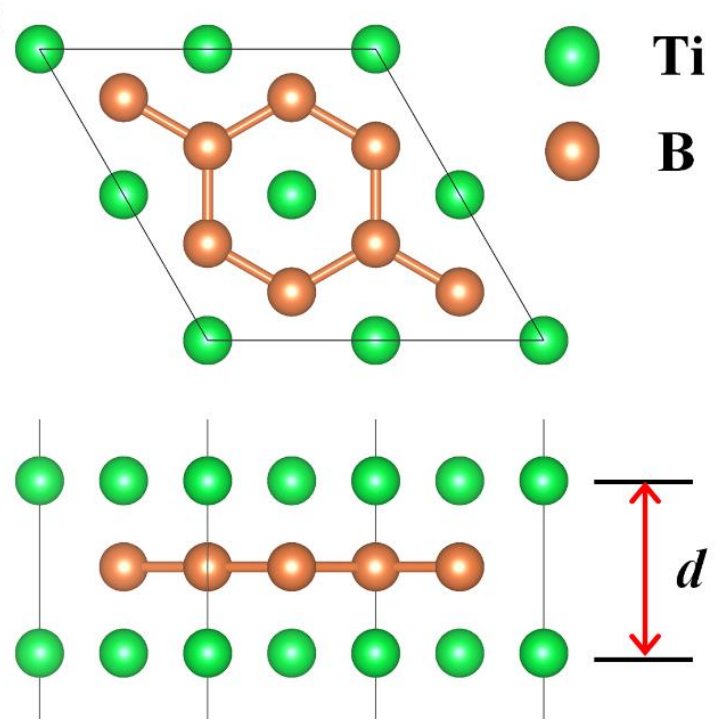

(b)
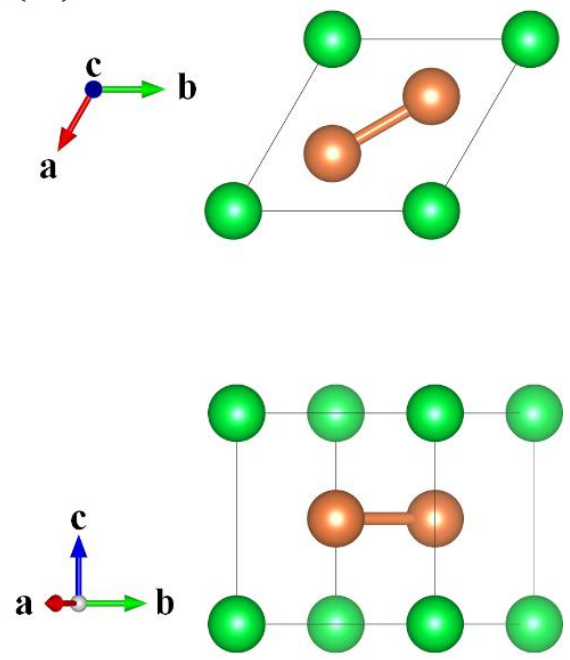

Fig. 1. Top and side views of (a) global minimum phase of $\mathrm{Ti}_{2} \mathrm{~B}_{2}$ monolayer and (b) bulk $\mathrm{TiB}_{2}$. The Ti and $\mathrm{B}$ atoms are denoted by green and orange spheres, respectively.

Motivated by the excellent performance of the MXenes in energy storage [70], we investigate TM-B systems characterized by 2D "sandwich" structures. Interestingly, through structural prediction by using the CALYPSO code, we find several $2 \mathrm{D} \mathrm{Ti}{ }_{2} \mathrm{~B}_{2}$ structures. The global minimum structure is shown in Fig. 1a and the other metastable isomers in Fig. S1 in the Supplementary information (SI). The obtained orthorhombic $2 \mathrm{D} \mathrm{Ti}_{2} \mathrm{~B}_{2}$ monolayer (Fig. S1a) possesses the same structure as those of $2 \mathrm{D} \mathrm{Fe}_{2} \mathrm{~B}_{2}$ and $\mathrm{Mo}_{2} \mathrm{~B}_{2}$ reported by Guo et al [60]. According to our calculations, the energy of this orthorhombic $2 \mathrm{D} \mathrm{Ti} 2 \mathrm{~B}_{2}$ monolayer is higher by 0.067 $\mathrm{eV}$ per atom than that of the obtained hexagonal $2 \mathrm{D} \mathrm{Ti}_{2} \mathrm{~B}_{2}$ which is the global minimum structure (Fig. 1a). This hexagonal $2 \mathrm{D} \mathrm{Ti}_{2} \mathrm{~B}_{2}$ consists of an intermediate boron honeycomb sheet sandwiched in between two hexagonal planes of $\mathrm{Ti}$ atoms. 
Each boron atom bonds to three boron neighbors and the calculated B-B bond length is $1.734 \AA$. The line charge density distribution along B-B bond is $0.121 \mathrm{e} / \mathrm{au}^{3}$, which is larger than $0.104 \mathrm{e} / \mathrm{au}^{3}$ found for the Si covalent bond [71]. This indicates that the $\mathrm{B}$ layers are strongly bonded by B-B covalent bonds. Each Ti atom bonds to six B neighbors and the calculated Ti-B bond length is $2.332 \AA$. The bulk phase of this $2 \mathrm{D}$ structure crystallize in the hexagonal $P 6 / \mathrm{mmm}$ space group ( $\mathrm{AlB}_{2}$ type No. 191) with $N=3$ in the unit cell stacked along the $c$-axis (see Fig. 1b). The atomic Wyckoff positions of bulk $\mathrm{TiB}_{2}$ are: $\mathrm{Ti}$ in $1 a(0,0,0)$ and $\mathrm{B}$ in $2 d(1 / 3,2 / 3,1 / 2)$ [72]. As far as we know, many hexagonal bulk $\mathrm{TMB}_{2}$ structures have been synthesized and all confirmed to possess layered structural properties [73-76]. Thus, we further investigate the viability in other $2 \mathrm{D} \mathrm{TM}_{2} \mathrm{~B}_{2}$ monolayer. By substituting the Ti atom in $2 \mathrm{D} \mathrm{Ti}{ }_{2} \mathrm{~B}_{2}$ by other TM atoms, we find that the hexagonal $2 \mathrm{D} \mathrm{TM}_{2} \mathrm{~B}_{2}$ geometry can be maintained for $\mathrm{TM}=\mathrm{Sc}, \mathrm{V}, \mathrm{Cr}, \mathrm{Y}, \mathrm{Zr}$, Mo.

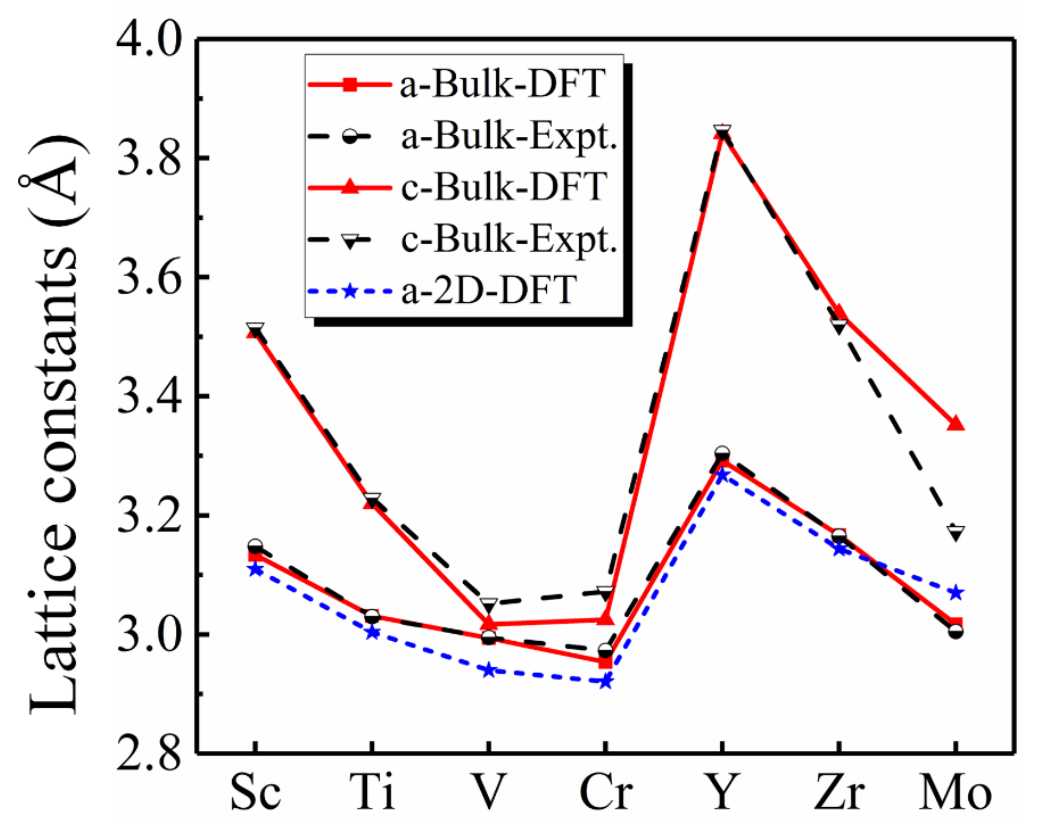

Fig. 2. Lattice constants of the bulk $\mathrm{TMB}_{2}$ phase and the $2 \mathrm{D} \mathrm{TM}_{2} \mathrm{~B}_{2}$ structure.

The optimized lattice constants (both $a$ and $c$ ) of these bulk $\mathrm{TMB}_{2}$ are shown in Fig. 2 and Table S1 in the SI, consistent well with the experimental results reported earlier [72-75, 77]. The optimized lattice constant of the $2 \mathrm{D} \mathrm{Ti}_{2} \mathrm{~B}_{2}$ is $a=b=3.004 \AA$, comparable to that of the bulk $\mathrm{TiB}_{2}(3.031 \AA)$ [72]. The optimized thickness of the $2 \mathrm{D}$ $\mathrm{Ti}_{2} \mathrm{~B}_{2}$ is $d=3.117 \AA$, also comparable to the lattice constant $c$ of the bulk $\mathrm{TiB}_{2}(3.220$ 
A) [72]. As shown in Fig. 2, the optimized lattice constants (a) of other six 2D TM $\mathrm{TB}_{2}$ are all consistent with those of their corresponding bulk structures. This indicates that these $2 \mathrm{D}$ structures are easily obtained from their corresponding bulk phases.
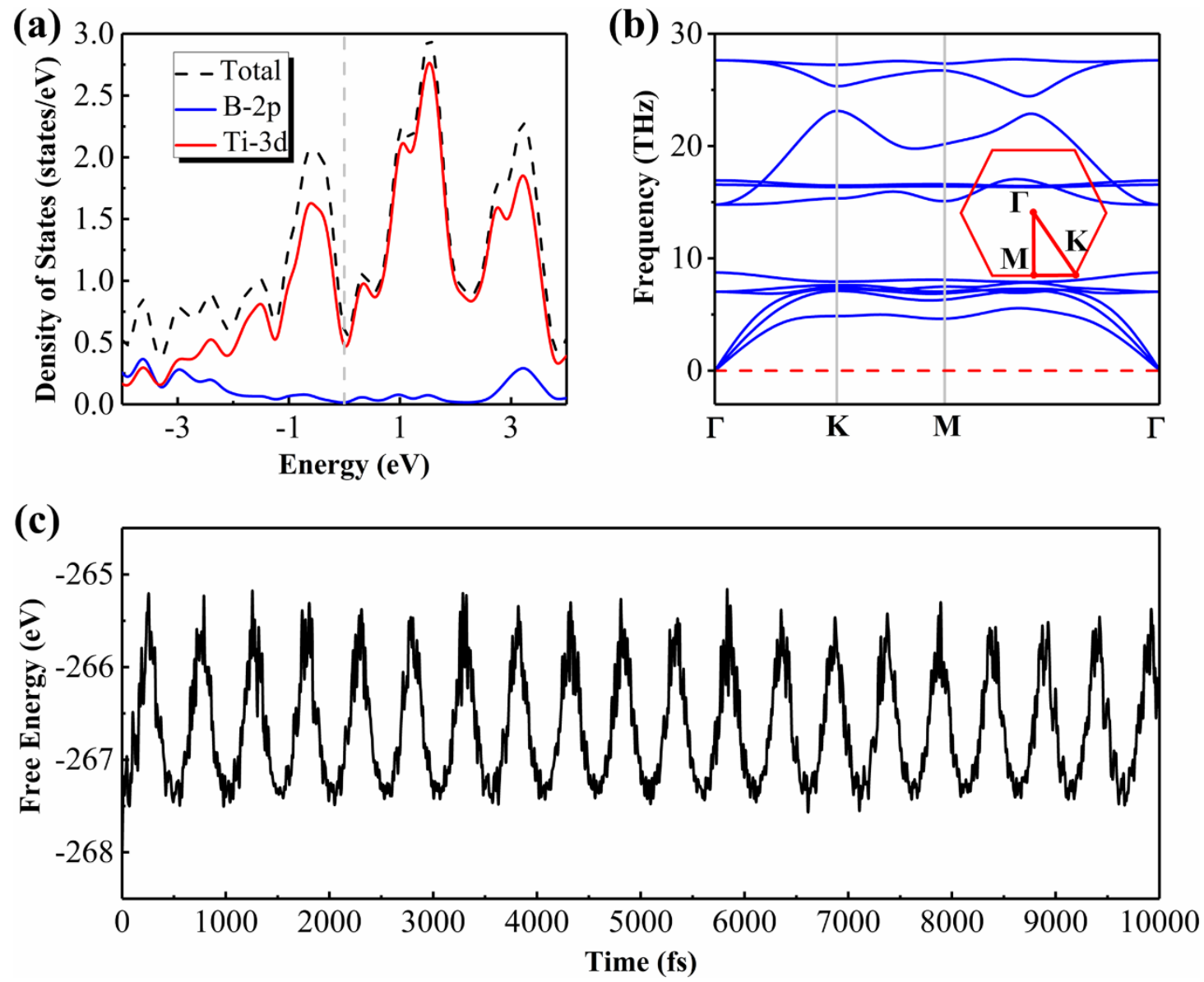

Fig. 3. (a) Total and partial density of states (TDOS and PDOS) of the $2 \mathrm{D} \mathrm{Ti}_{2} \mathrm{~B}_{2}$. The dash black line represents the TDOS while the solid red and solid blue lines stand for the Ti-3 $d$ and B- $2 p$ PDOS, respectively. The Fermi energy level is set at zero. (b) Phonon dispersion curves of the $2 \mathrm{D} \mathrm{Ti}_{2} \mathrm{~B}_{2}$. (c) Variation of the free energy in the AIMD simulations at $300 \mathrm{~K}$ during the time scale of $10 \mathrm{ps}$.

As shown in Fig. $3 \mathrm{a}$, the $2 \mathrm{D} \mathrm{Ti}_{2} \mathrm{~B}_{2}$ exhibits metallic property contributed mainly by the Ti- $3 d$ orbitals. The contribution from the B- $2 p$ is ignorable. The TDOS and PDOS of $2 \mathrm{D} \mathrm{Sc} \mathrm{S}_{2}, \mathrm{~V}_{2} \mathrm{~B}_{2}, \mathrm{Cr}_{2} \mathrm{~B}_{2}, \mathrm{Y}_{2} \mathrm{~B}_{2}, \mathrm{Zr}_{2} \mathrm{~B}_{2}$, and $\mathrm{Mo}_{2} \mathrm{~B}_{2}$ (shown in Fig. S2 in the SI) indicate that these six $2 \mathrm{D}$ materials, like $2 \mathrm{D} \mathrm{Ti}_{2} \mathrm{~B}_{2}$, present good conductivity. Owing to the outstanding electronic conductivity of these $2 \mathrm{D} \mathrm{TM}_{2} \mathrm{~B}_{2}$, they merit potential application as anode materials for LIBs and NIBs. 
The stability of anode materials is critical important due to hundreds of charge-discharge cycles in practical applications. To examine the dynamic stability of 2D Ti ${ }_{2} \mathrm{~B}_{2}$, we calculate its phonon dispersion curves. As shown in Fig. 3b, the absence of imaginary modes in the whole BZ confirms that $2 \mathrm{D} \mathrm{Ti}_{2} \mathrm{~B}_{2}$ is dynamically stable. The highest frequency of $2 \mathrm{D} \mathrm{Ti}_{2} \mathrm{~B}_{2}$ reaches up to $27.725 \mathrm{THz}\left(924 \mathrm{~cm}^{-1}\right)$, which is higher than those of $\mathrm{FeB}_{2}\left(854 \mathrm{~cm}^{-1}\right)$ [78], TiC $\left(810 \mathrm{~cm}^{-1}\right)$ [79], $\mathrm{Cu}_{2} \mathrm{Si}\left(420 \mathrm{~cm}^{-1}\right)$ [80], and $\mathrm{MoS}_{2}\left(473 \mathrm{~cm}^{-1}\right)$ [81] monolayers. The high value of frequencies in the phonon dispersion also indicates the stability of this $2 \mathrm{D}$ material. The phonon spectra of other six $2 \mathrm{D} \mathrm{TM}_{2} \mathrm{~B}_{2}$ are also calculated and shown in Fig. S3 in the SI. We find that these 2D $\mathrm{TM}_{2} \mathrm{~B}_{2}$ are also dynamically stable. To check the thermal stability, we carry out AIMD simulations for the $2 \mathrm{D} \mathrm{Ti}{ }_{2} \mathrm{~B}_{2}$ at temperatures of $300,600,1200,1800,2400$, and $3000 \mathrm{~K}$, respectively. At $300 \mathrm{~K}$, the average value of free energy remains almost constant during the whole simulation (see Fig. $3 \mathrm{c}$ ), confirming that the $2 \mathrm{D} \mathrm{Ti}_{2} \mathrm{~B}_{2}$ is thermally stable at room temperature. Even increasing the temperature up to $2400 \mathrm{~K}$, the original geometry remains intact with only slight in-plane and out-of-plane deformations (see Fig. S4). The free energies fluctuate around constant values during the AIMD simulation below and at $2400 \mathrm{~K}$ (see Fig. S5). These results confirm that the $2 \mathrm{D} \mathrm{Ti}_{2} \mathrm{~B}_{2}$ is stable upon heating, which, supplies safeguard for practical applications.

\subsection{Adsorption of $\mathrm{Li}$ and $\mathrm{Na}$ on the $2 \mathrm{D} \mathrm{Ti}_{2} \mathrm{~B}_{2}$ monolayer.}
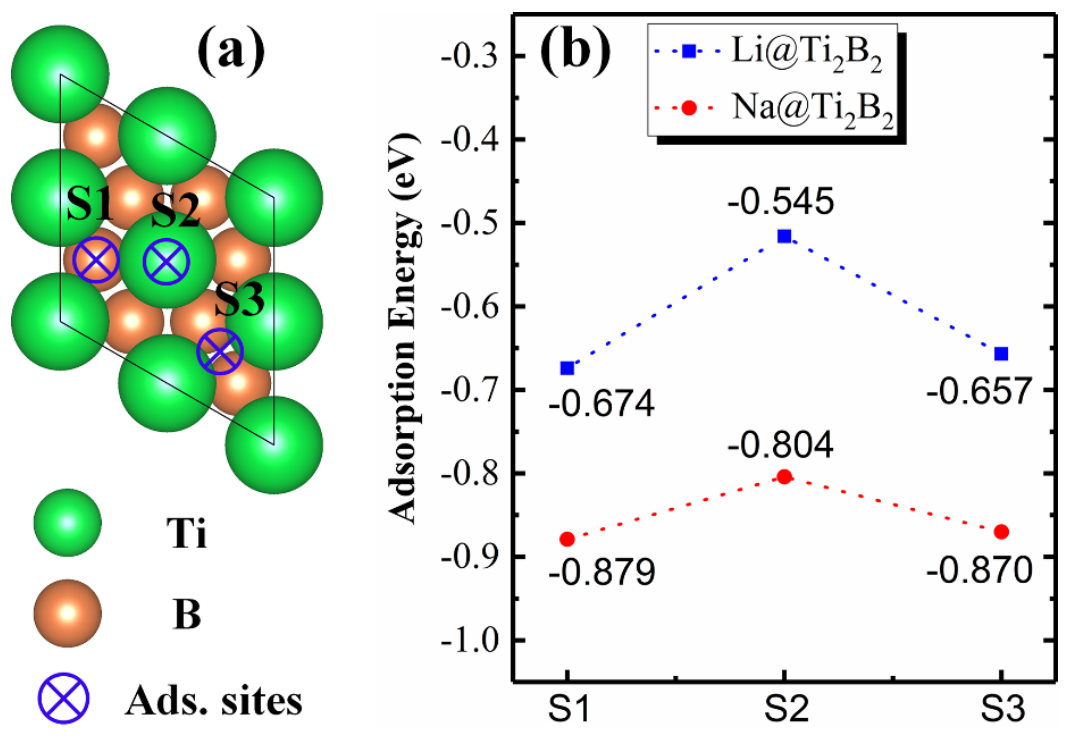
Fig. 4. (a) High symmetry adsorption sites and (b) adsorption energies for $\mathrm{Li} / \mathrm{Na}$ on the surface of $2 \mathrm{D} \mathrm{Ti}{ }_{2} \mathrm{~B}_{2}$. The Ti and $\mathrm{B}$ atoms are denoted by green and orange spheres, respectively.

The intrinsic metallicity and good stability of the $2 \mathrm{D} \mathrm{Ti}_{2} \mathrm{~B}_{2}$ make it a promising anode material for LIBs and NIBs. Next, we will further check its ability of adsorbing $\mathrm{Li} / \mathrm{Na}$ atoms. We first investigate the adsorption behaviors of a single $\mathrm{Li} / \mathrm{Na}$ atom on the surface of the $2 \mathrm{D} \mathrm{Ti}{ }_{2} \mathrm{~B}_{2}$ by considering three high symmetry adsorption sites $\mathrm{S} 1$, $\mathrm{S} 2$, and S3 (see Fig. 4a). The adsorption energies of $\mathrm{Li} / \mathrm{Na}$ atom on these sites are shown in Fig. 4b. We find that the Na-adsorbed configurations are more stable than the Li-adsorbed ones and the S1 is always the most stable adsorption site for both $\mathrm{Li}$ and $\mathrm{Na}$ atoms. Interestingly, the adsorption energies on S3 are very close to those on $\mathrm{S} 1$, suggesting that the $\mathrm{Li} / \mathrm{Na}$ atoms are easy to diffuse along the S1-S3-S1 direction, i.e. the B-B bonding direction. The adsorption energies on S2 are smaller by $0.06-0.13$ $\mathrm{eV}$ than those on $\mathrm{S} 1$ and $\mathrm{S} 3$. This indicates that the $\mathrm{Li} / \mathrm{Na}$ atom is not possible to appear on top of the Ti atoms. To better understand the adsorption properties of $\mathrm{Li} / \mathrm{Na}$ on the $\mathrm{Ti}_{2} \mathrm{~B}_{2}$ surface, we calculate the difference charge density and present them in Fig. 5 (Li-adsorption) and Fig. S6 (Na-adsorption). It is clear that the electrons tend to accumulate in between $\mathrm{Li} / \mathrm{Na}$ and its neighbor $\mathrm{Ti}$ atoms, thus, result in the $\mathrm{Li} / \mathrm{Na}-\mathrm{Ti}$ bonding. This chemical bonding between $\mathrm{Li} / \mathrm{Na}$ atoms and $2 \mathrm{D} \mathrm{Ti}_{2} \mathrm{~B}_{2}$ are favorable to prevent the forming of $\mathrm{Li} / \mathrm{Na}$ cluster and improve the safety and application availability for Li/Na storage in LIBs and NIBs.

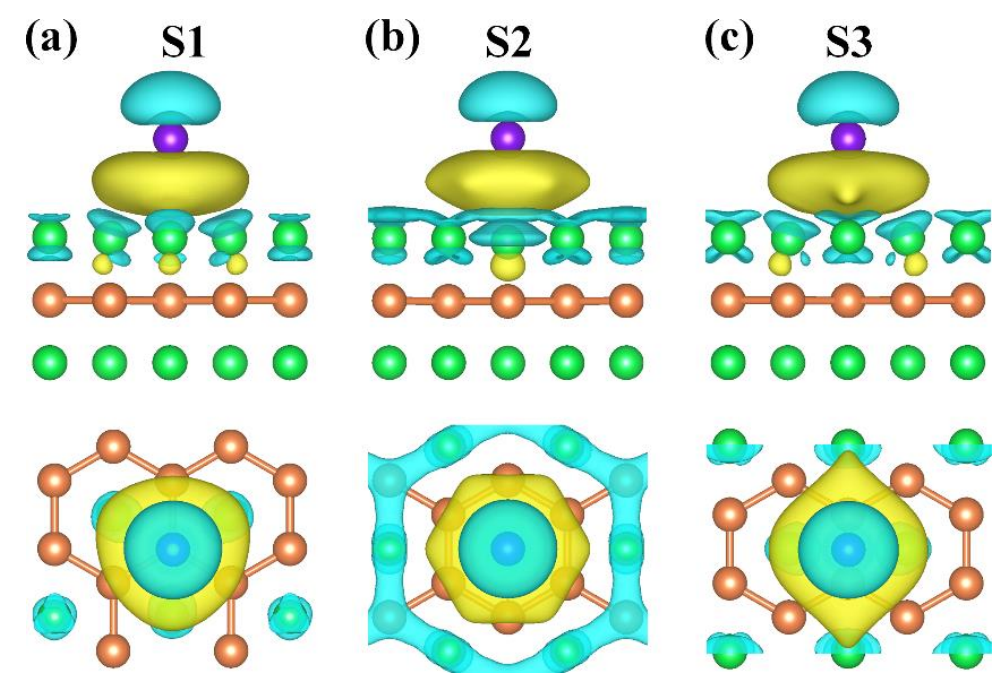


Fig. 5. The charge density difference plots for Li adsorption on the (a) S1, (b) S2, and (c) $\mathrm{S} 3$ sites of $2 \mathrm{D} \mathrm{Ti}_{2} \mathrm{~B}_{2}$ monolayer. The yellow and cyan areas represent electron gains and loses. The Ti, B, and Li atoms are denoted by green, orange, and violet spheres, respectively.

\subsection{Theoretical specific capacity and average open-circuit voltage.}

(a) $\mathrm{Ti}_{2} \mathrm{~B}_{2} \mathrm{Li}_{2}$
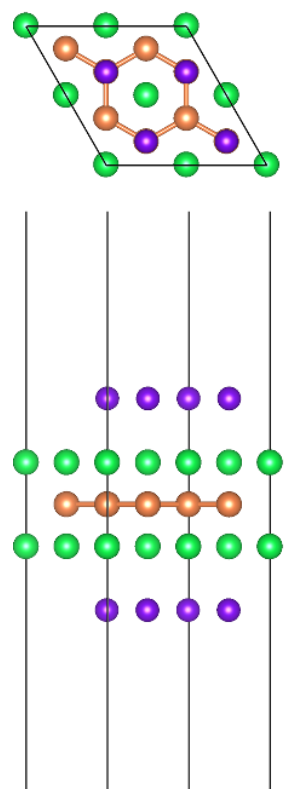

(b) $\mathrm{Ti}_{2} \mathrm{~B}_{2} \mathrm{Li}_{4}$
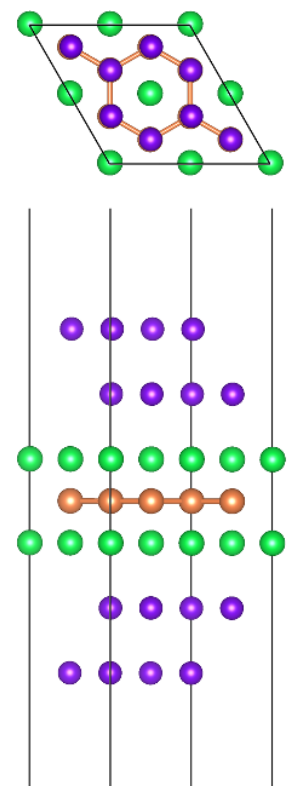

(c) $\mathrm{Ti}_{2} \mathrm{~B}_{2} \mathrm{Li}_{6}$
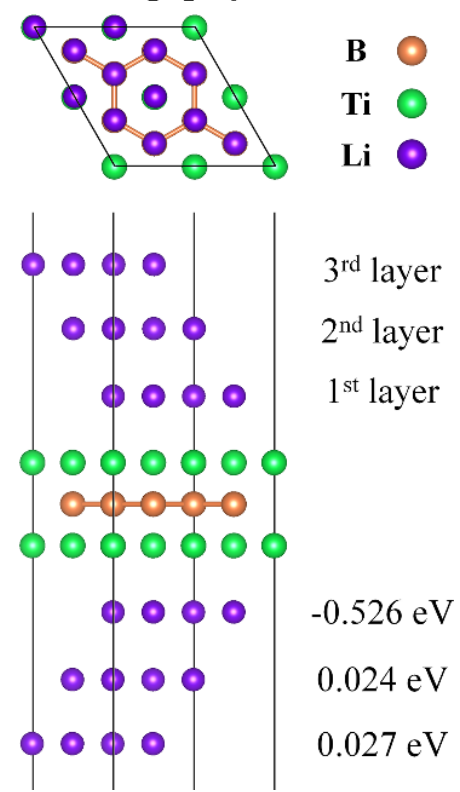

Fig. 6. Top and side views of the structures of (a) $\mathrm{Ti}_{2} \mathrm{~B}_{2} \mathrm{Li}_{2}$, (b) $\mathrm{Ti}_{2} \mathrm{~B}_{2} \mathrm{Li}_{4}$, and (c) $\mathrm{Ti}_{2} \mathrm{~B}_{2} \mathrm{Li}_{6}$ with layers of $\mathrm{Li}$ ions adsorbed on the surface of $2 \mathrm{D} \mathrm{Ti}{ }_{2} \mathrm{~B}_{2}$ monolayer. The $\mathrm{Ti}$, $\mathrm{B}$, and $\mathrm{Li}$ atoms are denoted by green, orange, and violet spheres, respectively.

For practical application, it is of great significance to investigate the storage capacity of the batteries for the electrode materials. Thus, the average adsorption energies are calculated to investigate the storage capacity of $\mathrm{Li} / \mathrm{Na}$ on the $\mathrm{Ti}_{2} \mathrm{~B}_{2}$ monolayer. The adsorptions of one, two, and three layers of $\mathrm{Li}$ on both sides of $\mathrm{Ti}_{2} \mathrm{~B}_{2}$ monolayer are investigated using $2 \times 2$ supercells and can be labeled as $\mathrm{Ti}_{2} \mathrm{~B}_{2} \mathrm{Li}_{\mathrm{x}}$ with $x=2,4$ and 6, respectively. For the one-layer adsorption, shown in Fig. 6a, all Li atoms are absorbed at the S1 sites. In condition of saturation, there are eight Li atoms that can be adsorbed on both sides of the $\mathrm{Ti}_{2} \mathrm{~B}_{2}$ monolayer. The average adsorption energy of $\mathrm{Li}$ atoms is $-0.526 \mathrm{eV}$, which indicates that $\mathrm{Li}$ adatoms can be adsorbed stably without clustering. After the first layer being adsorbed fully, the subsequently added 
$\mathrm{Li}$ atoms will form the second adsorbed layer. The $\mathrm{Li}$ atoms are also adsorbed at the S1 sites (see Fig. 6b). This can be regard as the two-layer adsorption and there are 16 Li atoms being adsorbed in condition of full adsorption. For the three-layer adsorption, the third-layer Li atoms are adsorbed at the S2 sites (Fig. 6c). In condition of full adsorption, there are $24 \mathrm{Li}$ atoms being adsorbed. The adsorption energies for one-layer, two-layer, and three-layer adsorption are $-4.208,-4.019$, and $-3.800 \mathrm{eV}$, respectively. However, according to Eq. (4), the calculated average adsorption energies for the second and third layers of $\mathrm{Li}$ atoms are 0.024 and $0.027 \mathrm{eV}$, respectively. The positive values of these adsorption energies mean that the adsorptions of two and three layers of Li are not stable in energy. The above results reveal that the $2 \times 2$ supercell of $\mathrm{Ti}_{2} \mathrm{~B}_{2}$ monolayer can accumulate $8 \mathrm{Li}$ atoms at most, corresponding to $\mathrm{Ti}_{2} \mathrm{~B}_{2} \mathrm{Li}_{2}$ with symmetric configuration of adatoms on both sides of $\mathrm{Ti}_{2} \mathrm{~B}_{2}$ monolayer. According to these results and Eqs (3) and (5), the corresponding theoretical specific capacity and average open-circuit voltage of the $2 \mathrm{D} \mathrm{Ti}_{2} \mathrm{~B}_{2}$ as electrode of LIBs are $\sim 456 \mathrm{~mA} \mathrm{~h} \mathrm{~g}^{-1}$ and $0.526 \mathrm{eV}$, respectively. 


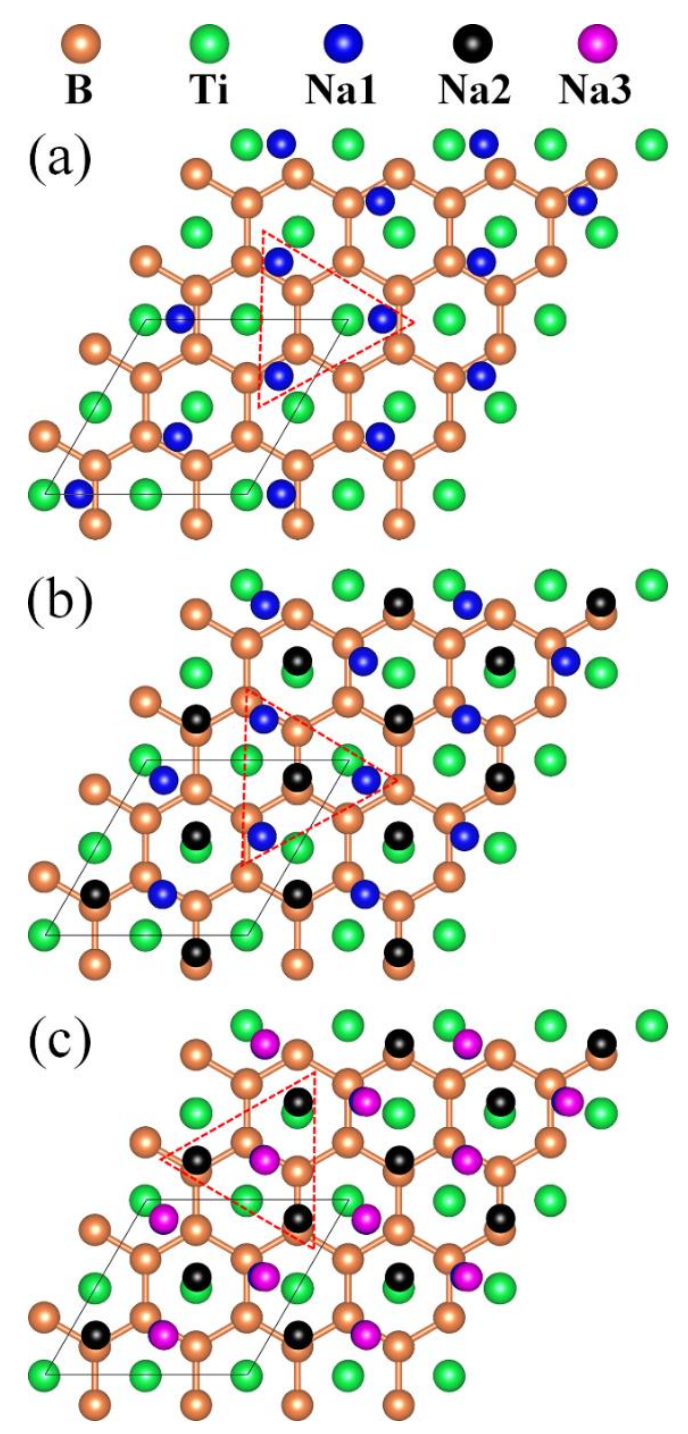

Fig. 7. Top views of (a) one-layer, (b) two-layers, and (c) three-layers adsorptions of $\mathrm{Na}$ ions on the $2 \mathrm{D} \mathrm{Ti}_{2} \mathrm{~B}_{2}$ monolayer. $\mathrm{Na} 1, \mathrm{Na} 2$, and $\mathrm{Na} 3$ represent the $\mathrm{Na}$ ions adsorbed in the first, the second, and the third layer, respectively. The black lines stand for the range of a $2 \times 2$ supercell.

Next, we turn our focus on the case of $\mathrm{Na}$-adsorbed $\mathrm{Ti}_{2} \mathrm{~B}_{2}$ system. The one-layer, two-layers, and three-layers adsorptions of $\mathrm{Na}$ on both sides of $2 \mathrm{D} \mathrm{Ti}_{2} \mathrm{~B}_{2}$ are calculated and the corresponding schematic pictures are presented in Fig. 7. For clarity, only $\mathrm{Na}$ atoms on single side of the $2 \mathrm{D} \mathrm{Ti}_{2} \mathrm{~B}_{2}$ are shown in this figure. The first layer can accommodate at most six $\mathrm{Na}$ atoms on both sides of the $\mathrm{Ti}_{2} \mathrm{~B}_{2}$ monolayer, three $\mathrm{Na}$ atoms on each side. This number is less than that of Li adsorption. Since the atomic radius of $\mathrm{Na}$ is larger than that of $\mathrm{Li}$, this fact is understandable. As shown in Fig. 7a, the three $\mathrm{Na}$ atoms form an equilateral triangle and the adsorption sites are 
not at the S1. When the first layer is adsorbed fully, the additionally added $\mathrm{Na}$ atoms will form the second layer at the sites above the center of the equilateral triangles (Fig. 7b). The adsorption sites for the third layer are above the center of the equilateral triangles of the second layer (Fig. 7c). The second and the third layers can also accommodate as many as six $\mathrm{Na}$ atoms on both sides. The average adsorption energies are all negative for the first, the second, and the third layers $(-0.502,-0.007$, and $-0.009 \mathrm{eV}$, respectively), indicating that $\mathrm{Na}$ atoms can be adsorbed stably without clustering. Furthermore, the adsorption of four layers of $\mathrm{Na}$ on the $\mathrm{Ti}_{2} \mathrm{~B}_{2}$ monolayer is not energetically stable according to our calculation. The above results reveal that the $2 \times 2$ supercell of $\mathrm{Ti}_{2} \mathrm{~B}_{2}$ monolayer can accommodate $18 \mathrm{Na}$ adatoms, corresponding to $\mathrm{Ti}_{2} \mathrm{~B}_{2} \mathrm{Na}$ 4.5. Therefore, the calculated theoretical specific capacity of the $2 \mathrm{D} \mathrm{Ti}_{2} \mathrm{~B}_{2}$ as electrode of NIBs is $\sim 1027 \mathrm{~mA} \mathrm{~h} \mathrm{~g}^{-1}$. The average open-circuit voltage decreases from 0.502 , via 0.255 , to $0.173 \mathrm{eV}$ with increasing of the adsorbed $\mathrm{Na}$ atoms from 6 , via 12 , to 18 .

We also estimate the varying of lattice constant and thickness of the $\mathrm{Ti}_{2} \mathrm{~B}_{2}$ monolayer after the adsorption of layered $\mathrm{Li} / \mathrm{Na}$ atoms. The lattice constant increases from $6.008\left(\mathrm{Ti}_{2} \mathrm{~B}_{2}\right)$ to $6.047 \AA\left(\mathrm{Ti}_{2} \mathrm{~B}_{2} \mathrm{Li}_{2}\right)$ for $\mathrm{Li}$ adsorption (about $0.65 \%$ tensile strain), and slightly increases from $6.008\left(\mathrm{Ti}_{2} \mathrm{~B}_{2}\right), 6.040\left(\mathrm{Ti}_{2} \mathrm{~B}_{2} \mathrm{Na}_{1.5}\right)$, and 6.054 $\left(\mathrm{Ti}_{2} \mathrm{~B}_{2} \mathrm{Na}_{3}\right)$ to $6.070 \AA\left(\mathrm{Ti}_{2} \mathrm{~B}_{2} \mathrm{Na}_{4.5}\right)$ for $\mathrm{Na}$ adsorption (about $1.03 \%$ tensile strain). The calculated thickness of the $\mathrm{Ti}_{2} \mathrm{~B}_{2}$ monolayer for the one-layer adsorbed $\mathrm{Li}$ structure $\left(\mathrm{Ti}_{2} \mathrm{~B}_{2} \mathrm{Li}_{2}\right)$ is $3.128 \AA$, which is larger by $0.29 \%$ than that of the bare monolayer $(3.119$ $\AA$ ). However, the thicknesses of the $\mathrm{Ti}_{2} \mathrm{~B}_{2}$ monolayer for the one-layer $\left(\mathrm{Ti}_{2} \mathrm{~B}_{2} \mathrm{Na}_{1.5}\right)$, two-layer $\left(\mathrm{Ti}_{2} \mathrm{~B}_{2} \mathrm{Na}_{3}\right)$, and three-layer $\left(\mathrm{Ti}_{2} \mathrm{~B}_{2} \mathrm{Na}_{4.5}\right)$ adsorptions of $\mathrm{Na}$ are 3.108, 3.106, and $3.110 \AA$, respectively. These values are smaller by $0.35 \%, 0.42 \%$, and $0.29 \%$ than the bare one, respectively. In view of these results, the $\mathrm{Ti}_{2} \mathrm{~B}_{2}$ monolayer is robust to be used as anode material in both LIBs and NIBs. 


\subsection{Electronic structures of the $2 \mathrm{D} \mathrm{Ti}_{2} \mathrm{~B}_{2}$ monolayer with adsorbed $\mathrm{Li} / \mathrm{Na}$ atoms.}

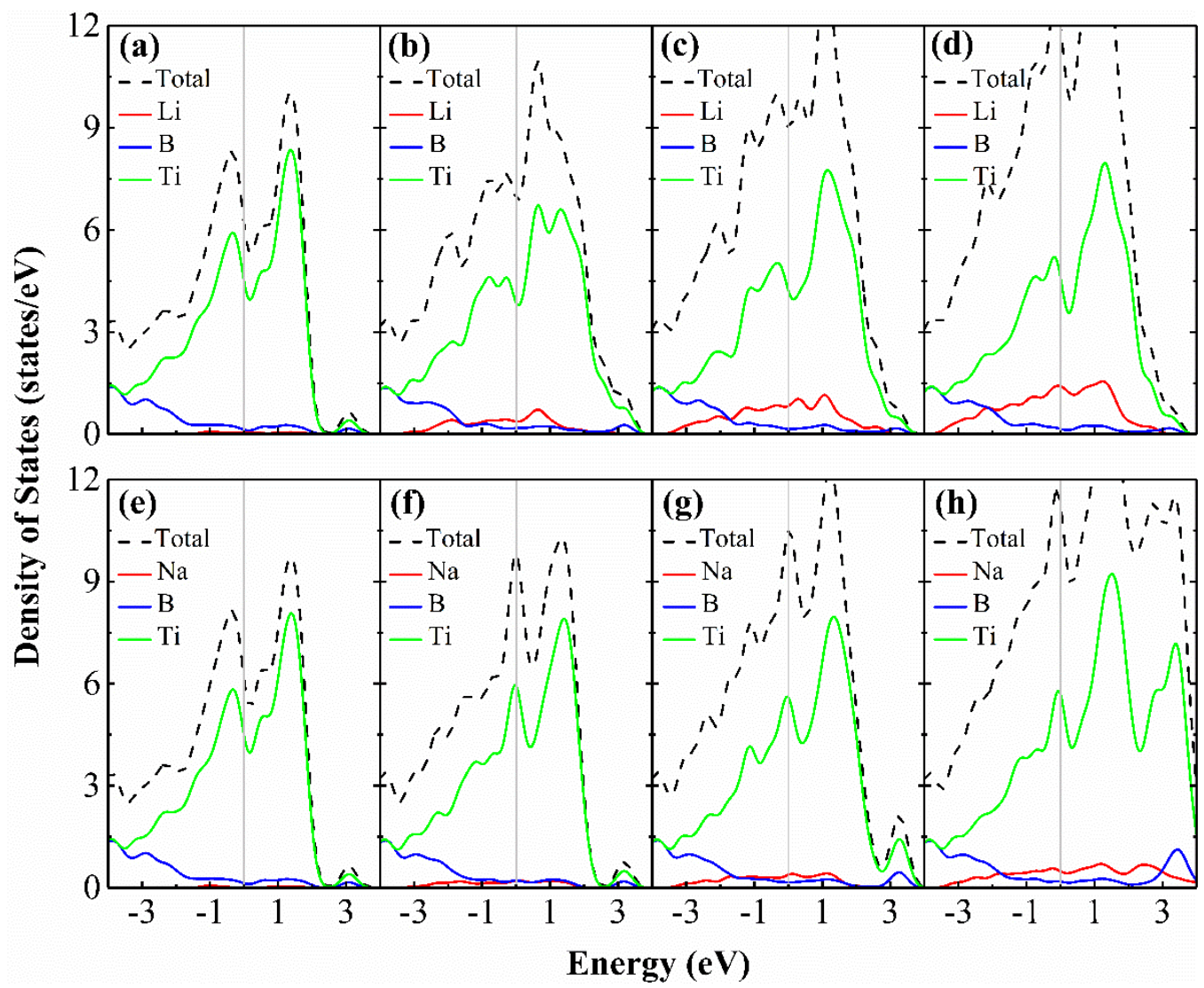

Fig. 8. TDOS and PDOS of the $2 \mathrm{D} \mathrm{Ti}_{2} \mathrm{~B}_{2}$ monolayer adsorbed with (a) one $\mathrm{Li}$ atom, (b) one-layer Li atoms, (c) two-layer Li atoms, (d) three-layer Li atoms, (e) one $\mathrm{Na}$ atom, (f) one-layer $\mathrm{Na}$ atoms, (g) two-layer $\mathrm{Na}$ atoms, and (h) three-layer $\mathrm{Na}$ atoms, respectively. The Fermi energy levels are set as zero.

It is well known that the electronic conductivity is closely associated with the rate capability of the anode materials in LIBs and NIBs. Unlike many other 2D materials that exhibit semi-conducting or semi-metallic characteristics $[82,83]$, our previous analyses have demonstrated that the pristine $\mathrm{Ti}_{2} \mathrm{~B}_{2}$ monolayer exhibits intrinsic metallic behavior, which means a remarkable battery performance for the sheet. In order to gain insight into the electronic conductivity of the charge-discharge process, the evolutions of DOS for $\mathrm{Ti}_{2} \mathrm{~B}_{2}$ monolayer adsorbed with $\mathrm{Li} / \mathrm{Na}$ atoms are calculated (Fig. 8). Fig. 8a shows the DOS of single $\mathrm{Li}$ adsorbed on the $\mathrm{Ti}_{2} \mathrm{~B}_{2}$ monolayer. Compared to the DOS of the pristine $\mathrm{Ti}_{2} \mathrm{~B}_{2}$ monolayer (Fig. 3a), we find that the orbital contributions around the Fermi level mainly come from the sheet with 
negligible components from the $\mathrm{Li}$ atoms, endowing the system with metallic characteristic. To be mentioned that $\mathrm{Ti}_{2} \mathrm{~B}_{2}$ monolayer is easy to be terminated with multiple $\mathrm{Li}$ atoms, hence the modulation effect of surface atomic number on electronic structures has also been evaluated in the following sequence: one-layer (Fig. 8b), two-layer (Fig. 8c), and three-layer (Fig. 8d) adsorbed Li configurations. With the Li concentration increasing during the charging process, the orbital contributions from $\mathrm{Li}$ atoms near the Fermi level increase with the components of the monolayer showing no big fluctuations. Meanwhile, the Fermi level is getting away from the valley bottom of the DOS with the increasing number of $\mathrm{Li}$ atoms, indicating the growing instability of the system. These simulations explicitly demonstrate that the system retains the metallic nature during $\mathrm{Li}$ atomic adsorption process. Similar evolutions of DOS, for the host $\mathrm{Ti}_{2} \mathrm{~B}_{2}$ monolayer with one-layer, two-layer, and three-layer $\mathrm{Na}$ adsorbed, are also found in Fig. 8. These robust electronic properties of $\mathrm{Ti}_{2} \mathrm{~B}_{2}$ monolayer greatly expand its potential applications in anode materials and motivate subsequent experimental studies.

\section{5 $\mathrm{Li} / \mathrm{Na}$ diffusion on $2 \mathrm{D} \mathrm{Ti}_{2} \mathrm{~B}_{2}$ monolayer.}
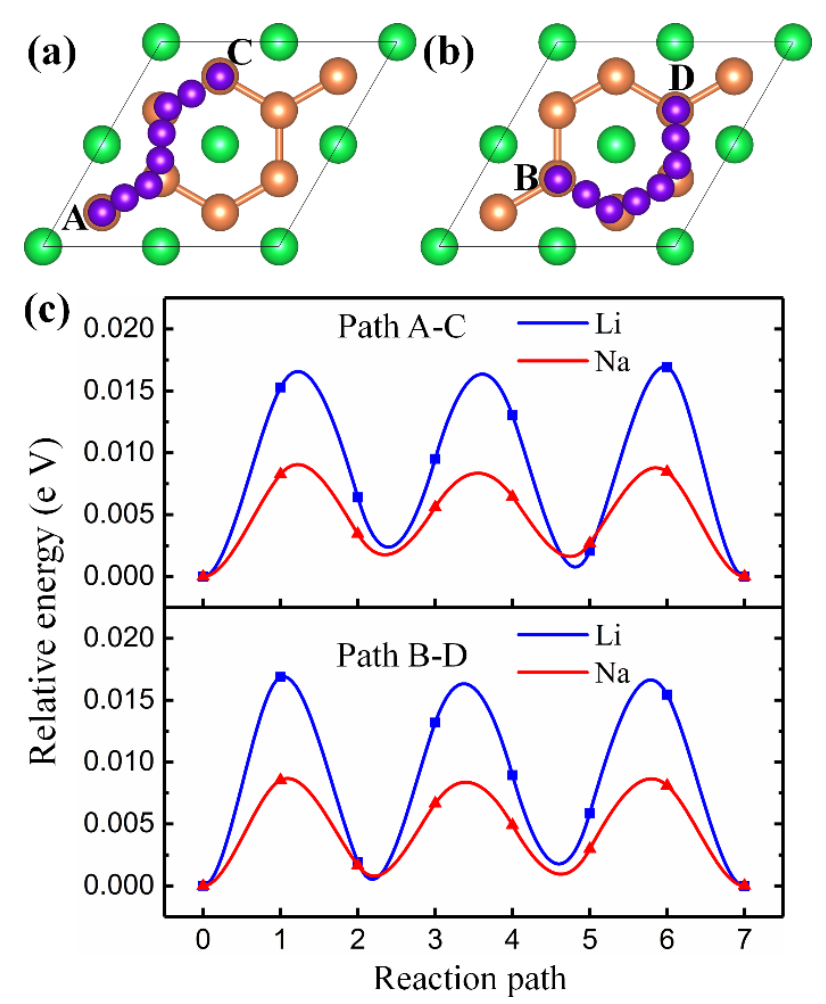
Fig. 9. Top view of two pathways, (a) Path A-C and (b) Path B-D, for Li/Na diffusion on the $2 \mathrm{D} \mathrm{Ti}{ }_{2} \mathrm{~B}_{2}$ monolayer. The $\mathrm{Ti}, \mathrm{B}$, and $\mathrm{Li} / \mathrm{Na}$ atoms are denoted by green, orange, and violet spheres, respectively. (c) Energy profiles of the corresponding $\mathrm{Li}$ and $\mathrm{Na}$ diffusion pathways.

In addition to the high specific capacity, a good charge-discharge rate capability is of great significance for a promising anode material for LIBs and NIBs. The diffusion barrier of $\mathrm{Li} / \mathrm{Na}$ is a key factor that determines the charge-discharge rate. In this part, we employ the CI-NEB method to investigate the diffusion barriers for Li and $\mathrm{Na}$ atoms on the surface of $\mathrm{Ti}_{2} \mathrm{~B}_{2}$ monolayer. As $\mathrm{Li}$ and $\mathrm{Na}$ atoms preferentially occupy the S1 site, two possible pathways starting from one S1 site to another S1 site are considered. The first pathway is from A to C (Fig. 9a) and the second from B to D (Fig. 9b). Both these pathways are connected by four S1 and three S3 sites and can be viewed as S1-S3-S1-S3-S1-S3-S1. As illustrated in Fig. 9c, the energy barriers for Li diffusion along the A-C and B-D pathways are both $0.017 \mathrm{eV}$ while that for $\mathrm{Na}$ diffusion are both $0.008 \mathrm{eV}$. The ultralow diffusion energy barriers indicate that $\mathrm{Li}$ and $\mathrm{Na}$ atoms can diffuse extremely easy on the $\mathrm{Ti}_{2} \mathrm{~B}_{2}$ monolayer. Furthermore, due to the smaller diffusion energy barrier of $\mathrm{Na}$ than that of $\mathrm{Li}$, the $\mathrm{Na}$ ions are easier to diffuse on the $\mathrm{Ti}_{2} \mathrm{~B}_{2}$ monolayer than $\mathrm{Li}$ ions. The larger rate capacity for $\mathrm{Na}$ than $\mathrm{Li}$ is also found in other 2D materials, such as $\mathrm{B}_{2} \mathrm{H}_{2}$ [35] and $\mathrm{Mo}_{2} \mathrm{C}$ [38]. Here, the low diffusion energy barriers are due to the small difference of the $\mathrm{Li} / \mathrm{Na}$ adsorption energies between the S1 and S3 sites. Since that the diffusion energy barriers for A-C and B-D pathways are the same, the two pathways are both possible routes for $\mathrm{Li} / \mathrm{Na}$ ion diffusion, which, would beneficial to increase the charge-discharge rate of LIBs and NIBs. 

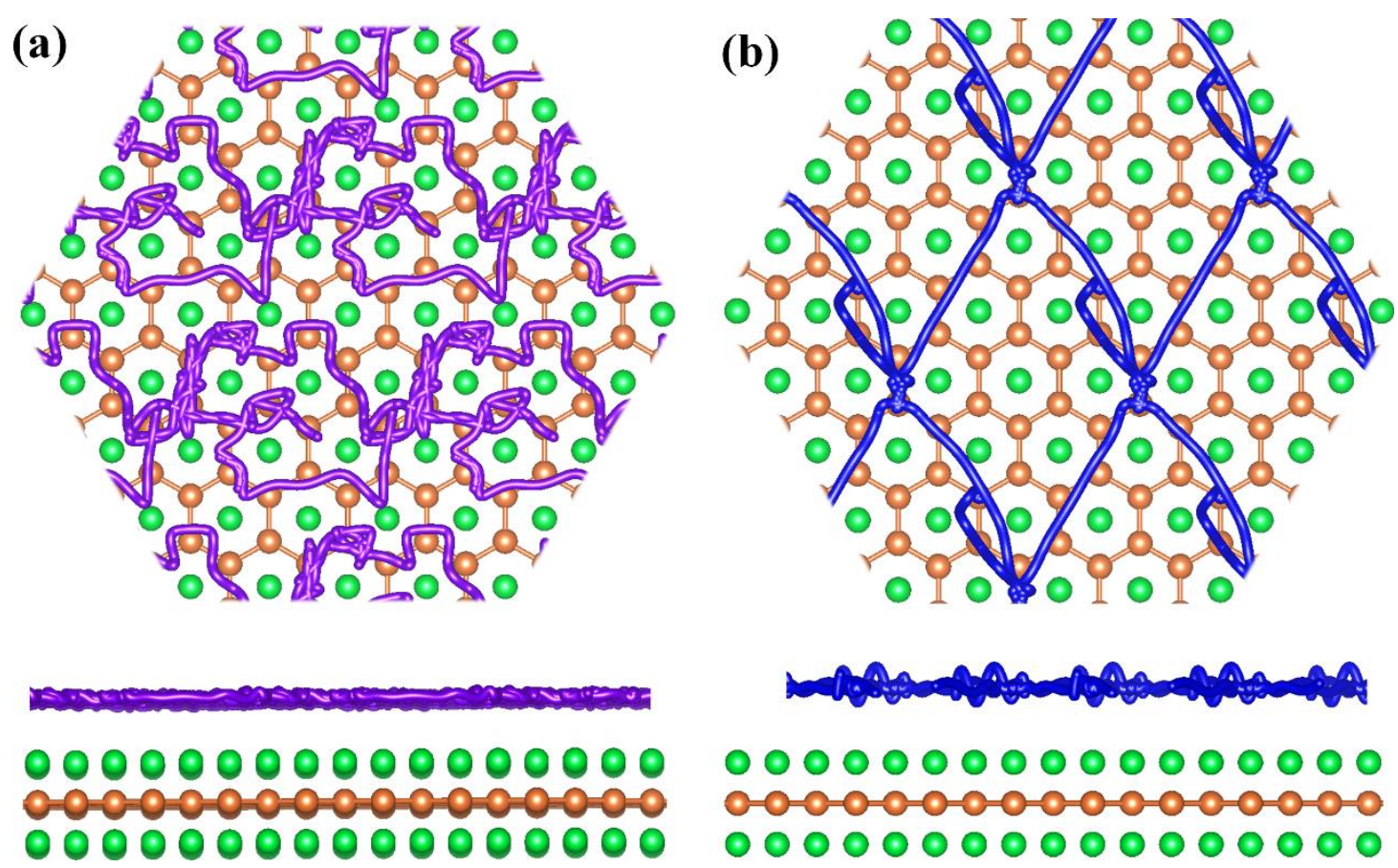

Fig. 10. Top and side views of the calculated (a) Li and (b) Na trajectories during the 10 ps AIMD simulations. The $\mathrm{Ti}, \mathrm{B}, \mathrm{Li}$, and $\mathrm{Na}$ atoms are denoted by green, orange, violet, and blue spheres, respectively.

To further investigate the diffusion kinetics of $\mathrm{Li}$ and $\mathrm{Na}$ atoms on the $\mathrm{Ti}_{2} \mathrm{~B}_{2}$ monolayer, the AIMD simulations are performed at $300 \mathrm{~K}$ lasting for $10 \mathrm{ps}$. The $\mathrm{Li}$ and $\mathrm{Na}$ diffusion trajectories during the 10 ps simulation, shown in Fig. 10a and 10b, respectively, give direct visualizations of $\mathrm{Li}$ and $\mathrm{Na}$ diffusion on the $\mathrm{Ti}_{2} \mathrm{~B}_{2}$ monolayer. We see that the Li atom can travel through the entire region almost freely along the A-C or B-D pathways, although the diffusion path is not that straight. Interestingly, the $\mathrm{Na}$ atom can diffuse through the entire region in almost straight lines along the A-C pathway. Similar behavior has been observed on borophene for Li diffusion [29]. The above AIMD simulation results explicitly exhibit an ultra-fast $\mathrm{Li} / \mathrm{Na}$ diffusion on the $2 \mathrm{D} \mathrm{Ti}_{2} \mathrm{~B}_{2}$ monolayer, giving a proof that this $2 \mathrm{D}$ material is a promising candidate for the high rate LIBs and NIBs electrode materials.

\subsection{Comparison with other anode materials.}

In order to evaluate the superiority of our studied $\mathrm{Ti}_{2} \mathrm{~B}_{2}$ monolayer as an electrode material for LIBs and NIBs, we compare the theoretical specific capacity and diffusion barrier of it with other widely investigated anode materials [8, 29, 31, 33-35, 
38, 47-53, 60, 84-92] in Table 1 and Table 2. For Li storage, the theoretical specific capacity of the $\mathrm{Ti}_{2} \mathrm{~B}_{2}$ monolayer is $456 \mathrm{mAhg}^{-1}$, which is greater than that of the well-established graphite $[8,84,85]$, phosphorene [50, 51], $\mathrm{Ti}_{3} \mathrm{C}_{2}[31]$, or $\mathrm{Li}_{4} \mathrm{Ti}_{5} \mathrm{O}_{12}$ [86], and comparable to that of the $\mathrm{Mo}_{2} \mathrm{C}$ [38], $\mathrm{VS}_{2}$ [48], $\mathrm{B}_{2} \mathrm{H}_{2}$ [35], and planar $\mathrm{TiB}_{4}$ [92]. Compared to the orthorhombic 2D MBenes [60], the theoretical specific capacity of the hexagonal $2 \mathrm{D} \mathrm{Ti}{ }_{2} \mathrm{~B}_{2}$ is in between those of the $2 \mathrm{D} \mathrm{Mo}_{2} \mathrm{~B}_{2}$ and the $2 \mathrm{D}$ $\mathrm{Fe}_{2} \mathrm{~B}_{2}$ [60]. Although the theoretical specific capacity is lower than that of silicon [87], silicene [49], and Sn $[86,88]$, the energy barrier $(0.017 \mathrm{eV})$ for Li diffusion is the lowest one among the listed materials in Table 1 besides borophene [29]. This indicates that the $2 \mathrm{D} \mathrm{Ti}_{2} \mathrm{~B}_{2}$ possesses a very high rate capability for Li diffusion.

In the case of $\mathrm{Na}$ storage and diffusion, as shown in Table 2, the $\mathrm{Ti}_{2} \mathrm{~B}_{2}$ monolayer has the second largest theoretical specific capacity. The value of $1027 \mathrm{mAhg}^{-1}$ is larger than that of phosphorene [89] and boron-doped graphene [90] and close to the highest theoretical specific capacity we found in literature for $\mathrm{Ca}_{2} \mathrm{~N}$ [34]. When compared with other $2 \mathrm{D}$ materials, the theoretical specific capacity of $\mathrm{Ti}_{2} \mathrm{~B}_{2}$ is about 2 to 3 times of that reported in $\mathrm{Ti}_{3} \mathrm{C}_{2}$ [33], borophene [53], $\mathrm{B}_{2} \mathrm{H}_{2}$ [35], and $\mathrm{Sr}_{2} \mathrm{~N}$ [34], and is more than 7 times of that reported in $\mathrm{MoS}_{2}$ [47] and $\mathrm{Mo}_{2} \mathrm{C}$ [38]. In addition, the diffusion energy barrier $(0.008 \mathrm{eV})$ of $\mathrm{Na}$ ion on $\mathrm{Ti}_{2} \mathrm{~B}_{2}$ monolayer is much lower than that of any other typical promising anode materials, shown in Table 2, indicating a very high rate capability.

In the end, we also compare the properties as an anode material for $2 \mathrm{D} \mathrm{Ti}_{2} \mathrm{~B}_{2}$ with the hexagonal 2D TiB 4 whose atomic stacking is B-Ti-B (Fig. S7a). The calculated energy of this $2 \mathrm{D} \mathrm{TiB}_{4}$ (Fig. S7a) is lower by $0.198 \mathrm{eV}$ per atom than the most stable planar 2D TiB 4 (Fig. S7b) [92], indicating the stability of this hexagonal 2D TiB 4 . The most stable adsorption sites and the corresponding adsorption energies are presented in Fig. S8. The $2 \times 2$ supercell of the hexagonal $2 \mathrm{D} \mathrm{TiB} 4$ can accommodate $8 \mathrm{Li}$ or $\mathrm{Na}$ atoms (Fig. S9), corresponding to $\mathrm{TiB}_{4} \mathrm{Li}_{2}$ and $\mathrm{TiB}_{4} \mathrm{Na}_{2}$, respectively. The theoretical specific capacity of this hexagonal $2 \mathrm{D} \mathrm{TiB}_{4}$ are both $588 \mathrm{mAhg}^{-1}$ for $\mathrm{Li}$ and $\mathrm{Na}$ storage, indicating a higher Li storage but a lower $\mathrm{Na}$ storage than those of the $2 \mathrm{D}$ 
$\mathrm{Ti}_{2} \mathrm{~B}_{2}$. However, the diffusion energy barriers of $\mathrm{Li}(0.712 \mathrm{eV})$ and $\mathrm{Na}(0.377 \mathrm{eV})$ on the hexagonal 2D TiB 4 are much larger than those on the $2 \mathrm{D} \mathrm{Ti}_{2} \mathrm{~B}_{2}$ (Fig. S10), indicating that the $2 \mathrm{D} \mathrm{Ti}_{2} \mathrm{~B}_{2}$ is more suitable to be an electrode material than the $2 \mathrm{D}$ $\mathrm{TiB}_{4}$.

Table 1. Summary of theoretical specific capacities $\left(\mathrm{mAhg}^{-1}\right)$ and diffusion barriers $(\mathrm{meV})$ of some widely investigated promising anode materials for LIBs.

\begin{tabular}{cccc}
\hline Species & Theoretical specific capacity & Diffusion barrier & References \\
\hline $\mathrm{Ti}_{2} \mathrm{~B}_{2}$ & 456 & 17 & This work \\
Graphite & 372 & $450 \sim 1200$ & {$[8,84,85]$} \\
Phosphorene & 433 & 80 & {$[50,51]$} \\
Silicon & 4200 & 580 & {$[87]$} \\
Silicene & 954 & 230 & {$[49]$} \\
$\mathrm{Sn}$ & 994 & 390 & {$[86,88]$} \\
$1 \mathrm{~T}-\mathrm{Ti}_{3} \mathrm{C}_{2}$ & 320 & 70 & {$[31]$} \\
$1 \mathrm{H}_{-} \mathrm{Mo}_{2} \mathrm{C}$ & 526 & 35 & {$[38]$} \\
$\mathrm{VS}_{2}$ & 466 & 220 & {$[48]$} \\
Borophene $_{\mathrm{B}_{2} \mathrm{H}_{2}}$ & 1860 & 2.6 & {$[29]$} \\
Li $_{4} \mathrm{Ti}_{5} \mathrm{O}_{12}$ & 504 & 210 & {$[35]$} \\
Orthorhombic Fe & & 300 & {$[86,91]$} \\
Orthorhombic $\mathrm{Mo}_{2} \mathrm{~B}_{2}$ & 175 & 240 & {$[60]$} \\
$\mathrm{Planar} \mathrm{TiB}_{4}$ & 665 & 270 & {$[60]$} \\
\hline
\end{tabular}


Table 2. Summary of theoretical specific capacities $\left(\mathrm{mAhg}^{-1}\right)$ and diffusion barriers $(\mathrm{meV})$ of some widely investigated promising anode materials for NIBs.

\begin{tabular}{cccc}
\hline Species & Theoretical specific capacity & Diffusion barrier & References \\
\hline $\mathrm{Ti}_{2} \mathrm{~B}_{2}$ & 1027 & 8 & This work \\
Phosphorene & 865 & 40 & {$[52]$} \\
graphene & & 130 & {$[89]$} \\
Boron-doped graphene & 762 & $160-220$ & {$[90]$} \\
$1 \mathrm{~T}-\mathrm{MoS}_{2}$ & 146 & 280 & {$[47]$} \\
$1 \mathrm{~T}-\mathrm{Ti}_{3} \mathrm{C}_{2}$ & 352 & 96 & {$[33]$} \\
$1 \mathrm{H}-\mathrm{Mo}_{2} \mathrm{C}$ & 132 & 15 & {$[38]$} \\
$\mathrm{Borophene}$ & $496 / 596$ & $300 / 12$ & {$[53]$} \\
$\mathrm{B}_{2} \mathrm{H}_{2}$ & 504 & 90 & {$[35]$} \\
$\mathrm{Ca}_{2} \mathrm{~N}$ & 1138 & 80 & {$[34]$} \\
$\mathrm{Sr}_{2} \mathrm{~N}$ & 283 & 16 & {$[34]$} \\
\hline
\end{tabular}

\section{Conclusion}

Searching for suitable electrode materials with good performance is urgently needed for energy storage. In this work, we firstly reported a series of hexagonal 2D transition metal borides (TMBs) including $\mathrm{Sc}_{2} \mathrm{~B}_{2}, \mathrm{Ti}_{2} \mathrm{~B}_{2}, \mathrm{~V}_{2} \mathrm{~B}_{2}, \mathrm{Cr}_{2} \mathrm{~B}_{2}, \mathrm{Y}_{2} \mathrm{~B}_{2}, \mathrm{Zr}_{2} \mathrm{~B}_{2}$, and $\mathrm{Mo}_{2} \mathrm{~B}_{2}$ by using first-principles method and crystal structure prediction techniques. Through the calculated phonon spectra and DOS, we confirmed that these TMBs possess great stability and excellent electronic conductivity.

Then, we investigated the potential of $2 \mathrm{D} \mathrm{Ti}_{2} \mathrm{~B}_{2}$ monolayer as the anode material for LIBs and NIBs on the basis of first-principles simulations. $\mathrm{The}^{\mathrm{Ti}} \mathrm{B}_{2} \mathrm{~B}_{2}$ monolayer shows negative adsorption energies for $\mathrm{Li}$ and $\mathrm{Na}$ of -0.674 and $-0.879 \mathrm{eV}$, respectively, on the most stable S1 site. The calculated theoretical specific capacity values for $\mathrm{Li}$ on $\mathrm{Ti}_{2} \mathrm{~B}_{2}$ monolayer is $456 \mathrm{mAhg}^{-1}$, which is larger than the well-established graphite, phosphorene, and $\mathrm{Ti}_{3} \mathrm{C}_{2}$. Interestingly, the theoretical specific capacity for $\mathrm{Na}$ is investigated to be $1027 \mathrm{mAhg}^{-1}$, which is much larger than 
most other 2D materials. More excitingly, we found that the $\mathrm{Ti}_{2} \mathrm{~B}_{2}$ monolayer shows very high Li and $\mathrm{Na}$ diffusivity with ultralow energy barrier of 0.017 and $0.008 \mathrm{eV}$, respectively, indicating an excellent charge-discharge capability for $\mathrm{Li}$ and $\mathrm{Na}$. Moreover, the $\mathrm{Ti}_{2} \mathrm{~B}_{2}$ monolayer was found to exhibit metallic nature after the adsorption of $\mathrm{Li}$ and $\mathrm{Na}$ ions at any concentrations, indicating that the $\mathrm{Ti}_{2} \mathrm{~B}_{2}$ monolayer possesses an excellent electronic conductivity. Finally, the $\mathrm{Ti}_{2} \mathrm{~B}_{2}$ monolayer just has a small change in volume after the adsorption of one, two, and three layers of $\mathrm{Li}$ and $\mathrm{Na}$ ions, indicating the robustness of this material.

Considering the above advantages, it is expected that the $\mathrm{Ti}_{2} \mathrm{~B}_{2}$ monolayer and its alike materials would be used as anode materials for LIBs and NIBs with high specific capacity and fast diffusivity.

\section{Corresponding Author}

*E-mail: wangbt@ihep.ac.cn

\section{Notes}

The authors declare no competing financial interest.

\section{Acknowledgments}

F.W.W. and J.R.Z. acknowledge financial support from National Natural Science Foundation of China under Grants No. 11675255, No. 11634008, and No. 11675195. J.R.Z. acknowledges financial support from The National Key Basic Research Program under Grants No. 2017YFA0403700. The calculations were performed at Supercomputer Centre in China Spallation Neutron Source.

\section{Supplementary information}

Supplementary information associated with this article can be found in the online version at:

(I) Computational method, (II) metastable isomers of $2 \mathrm{D} \mathrm{Ti}_{2} \mathrm{~B}_{2}$, (III) lattice constants

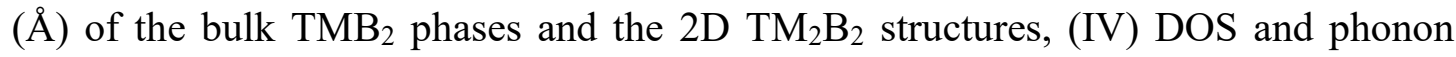


dispersion curves of the other six $2 \mathrm{D} \mathrm{TM}_{2} \mathrm{~B}_{2}$, (V) snapshots and variation of the free energy for $2 \mathrm{D} \mathrm{Ti}_{2} \mathrm{~B}_{2}$ in the AIMD simulations from 300 to $3000 \mathrm{~K}$, (VI) charge density difference plots for $\mathrm{Na}$ adsorption, (VII) 2D TiB 4 structures and the adsorption and diffusion of $\mathrm{Li} / \mathrm{Na}$ on the hexagonal $\mathrm{TiB}_{4}$ monolayer.

\section{REFERENCES}

[1] J.R. Miller, Science 335 (2012) 1312-1313.

[2] A.S. Aricò, P. Bruce, B. Scrosati, J.-M. Tarascon, W. van Schalkwijk, Nat. Mater. 4 (2005) $366-377$.

[3] M. Armand, J.M. Tarascon, Nature 451 (2008) 652-657.

[4] D.P. Dubal, O. Ayyad, V. Ruiz, P. Gomez-Romero, Chem. Soc. Rev. 44 (2015) 1777-1790.

[5] Y. Idota, T. Kubota, A. Matsufuji, Y. Maekawa, T. Miyasaka, Science 276 (1997) 1395-1397.

[6] N. Oyama, T. Tatsuma, T. Sato, T. Sotomura, Nature 373 (1995) 598-600.

[7] P. Simon, Y. Gogotsi, B. Dunn, Science 343 (2014) 1210-1211.

[8] J.M. Tarascon, M. Armand, Nature 414 (2001) 359-367.

[9] M.S. Whittingham, Science 192 (1976) 1126-1127.

[10] Y. Wang, B. Liu, Q. Li, S. Cartmell, S. Ferrara, Z.D. Deng, J. Xiao, J. Power Sources 286 (2015) 330-345.

[11] A. Barré, B. Deguilhem, S. Grolleau, M. Gérard, F. Suard, D. Riu, J. Power Sources 241 (2013) 680-689.

[12] W. Luo, F. Shen, C. Bommier, H. Zhu, X. Ji, L. Hu, Accounts Chem. Res. 49 (2016) 231-240.

[13] N. Yabuuchi, K. Kubota, M. Dahbi, S. Komaba, Chem. Rev. 114 (2014) 11636-11682.

[14] H. Pan, Y.-S. Hu, L. Chen, Energ. Environ. Sci. 6 (2013) 2338-2360.

[15] M.D. Slater, D. Kim, E. Lee, C.S. Johnson, Adv. Funct. Mater. 23 (2013) 947-958.

[16] Y. Wang, R. Chen, T. Chen, H. Lv, G. Zhu, L. Ma, C. Wang, Z. Jin, J. Liu, Energ. Storage Mater. 4 (2016) 103-129.

[17] R. Zhao, J. Liu, J. Gu, Appl. Energ. 139 (2015) 220-229.

[18] Y. Lee, B. Son, J. Choi, J.H. Kim, M.-H. Ryou, Y.M. Lee, J. Power Sources 275 (2015) $712-719$. 
[19] M. Endo, C. Kim, K. Nishimura, T. Fujino, K. Miyashita, Carbon 38 (2000) 183-197.

[20] J.R. Dahn, T. Zheng, Y. Liu, J.S. Xue, Science 270 (1995) 590-593.

[21] M. Winter, J.O. Besenhard, M.E. Spahr, P. Novák, Adv. Mater. 10 (1998) 725-763.

[22] D.P. DiVincenzo, E.J. Mele, Phys. Rev. B 32 (1985) 2538-2553.

[23] S. Meini, R. Elazari, A. Rosenman, A. Garsuch, D. Aurbach, J. Phys. Chem. Lett. 5 (2014) 915-918

[24] D. Takamatsu, T. Nakatsutsumi, S. Mori, Y. Orikasa, M. Mogi, H. Yamashige, K. Sato, T. Fujimoto, Y. Takanashi, H. Murayama, M. Oishi, H. Tanida, T. Uruga, H. Arai, Y. Uchimoto, Z. Ogumi, J. Phys. Chem. Lett. 2 (2011) 2511-2514.

[25] K. Song, D.-H. Seo, M.R. Jo, Y.-I. Kim, K. Kang, Y.-M. Kang, J. Phys. Chem. Lett. 5 (2014) 1368-1373.

[26] W. Sun, Y. Li, B. Wang, X. Jiang, M.I. Katsnelson, P. Korzhavyi, O. Eriksson, I. Di Marco, Nanoscale 8 (2016) 15753-15762.

[27] P.F. Liu, Y. Wu, T. Bo, L. Hou, J. Xu, H.J. Zhang, B.T. Wang, Phys. Chem. Chem. Phys. 20 (2018) 732-737.

[28] A. Gupta, T. Sakthivel, S. Seal, Prog. Mater. Sci. 73 (2015) 44-126.

[29] H.R. Jiang, Z. Lu, M.C. Wu, F. Ciucci, T.S. Zhao, Nano Energy 23 (2016) 97-104.

[30] C. Eames, M.S. Islam, J. Am. Chem. Soc. 136 (2014) 16270-16276.

[31] Q. Tang, Z. Zhou, P. Shen, J. Am. Chem. Soc. 134 (2012) 16909-16916.

[32] Y. Xie, M. Naguib, V.N. Mochalin, M.W. Barsoum, Y. Gogotsi, X. Yu, K.W. Nam, X.Q. Yang, A.I. Kolesnikov, P.R. Kent, J. Am. Chem. Soc. 136 (2014) 6385-6394.

[33] D. Er, J. Li, M. Naguib, Y. Gogotsi, V.B. Shenoy, ACS Appl. Mater. Interfaces 6 (2014) 11173-11179

[34] J. Hu, B. Xu, S.A. Yang, S. Guan, C. Ouyang, Y. Yao, ACS Appl. Mater. Interfaces 7 (2015) 24016-24022.

[35] N.K. Jena, R.B. Araujo, V. Shukla, R. Ahuja, ACS Appl. Mater. Interfaces 9 (2017) $16148-16158$.

[36] H.R. Jiang, W. Shyy, M. Liu, L. Wei, M.C. Wu, T.S. Zhao, J. Mater. Chem. A 5 (2017) $672-679$. 
[37] J. Liu, T. Zhao, S. Zhang, Q. Wang, Nano Energy 38 (2017) 263-270.

[38] Q. Sun, Y. Dai, Y. Ma, T. Jing, W. Wei, B. Huang, J. Phys. Chem. Lett. 7 (2016) 937-943.

[39] D. Wang, Y. Gao, Y. Liu, D. Jin, Y. Gogotsi, X. Meng, F. Du, G. Chen, Y. Wei, J. Phys. Chem. C 121 (2017) 13025-13034.

[40] Y. Zhou, X. Zu, Electrochim. Acta 235 (2017) 167-174.

[41] L. Dong, H. Kumar, B. Anasori, Y. Gogotsi, V.B. Shenoy, J. Phys. Chem. Lett. 8 (2017) $422-428$

[42] R.P. Joshi, B. Ozdemir, V. Barone, J.E. Peralta, J. Phys. Chem. Lett. 6 (2015) 2728-2732.

[43] Q. Peng, Z. Wang, B. Sa, B. Wu, Z. Sun, ACS Appl. Mater. Interfaces 8 (2016) 13449-13457.

[44] Q. Peng, K. Hu, B. Sa, J. Zhou, B. Wu, X. Hou, Z. Sun, Nano Res. 10 (2017) 3136-3150.

[45] M. Liang, L. Zhi, J. Mater. Chem. 19 (2009) 5871-5878.

[46] G. Kucinskis, G. Bajars, J. Kleperis, J. Power Sources 240 (2013) 66-79.

[47] M. Mortazavi, C. Wang, J. Deng, V.B. Shenoy, N.V. Medhekar, J. Power Sources 268 (2014) 279-286

[48] Y. Jing, Z. Zhou, C.R. Cabrera, Z. Chen, J. Phys. Chem. C 117 (2013) 25409-25413.

[49] G.A. Tritsaris, E. Kaxiras, S. Meng, E. Wang, Nano Lett. 13 (2013) 2258-2263.

[50] R. Zhang, X. Wu, J. Yang, Nanoscale 8 (2016) 4001-4006.

[51] W. Li, Y. Yang, G. Zhang, Y.-W. Zhang, Nano Lett. 15 (2015) 1691-1697.

[52] V.V. Kulish, O.I. Malyi, C. Persson, P. Wu, Phys. Chem. Chem. Phys. 17 (2015) 13921-13928.

[53] P. Liang, Y. Cao, B. Tai, L. Zhang, H. Shu, F. Li, D. Chao, X. Du, J. Alloy. Compd. 704 (2017) $152-159$.

[54] M. Naguib, O. Mashtalir, J. Carle, V. Presser, J. Lu, L. Hultman, Y. Gogotsi, M.W. Barsoum, ACS Nano 6 (2012) 1322-1331.

[55] M. Naguib, M. Kurtoglu, V. Presser, J. Lu, J. Niu, M. Heon, L. Hultman, Y. Gogotsi, M.W. Barsoum, Adv. Mater. 23 (2011) 4248-4253.

[56] J. Halim, S. Kota, M.R. Lukatskaya, M. Naguib, M.-Q. Zhao, E.J. Moon, J. Pitock, J. Nanda, S.J. May, Y. Gogotsi, M.W. Barsoum, Adv. Funct. Mater. 26 (2016) 3118-3127.

[57] K. Wang, Y. Zhou, W. Xu, D. Huang, Z. Wang, M. Hong, Ceram. Int. 42 (2016) 8419-8424. 
[58] A. Mishra, P. Srivastava, H. Mizuseki, K.-R. Lee, A.K. Singh, Phys. Chem. Chem. Phys. 18 (2016) 11073-11080.

[59] M. Naguib, Y. Gogotsi, Accounts Chem. Re. 48 (2015) 128-135.

[60] Z. Guo, J. Zhou, Z. Sun, J. Mater. Chem. A 5 (2017) 23530-23535.

[61] S. Ma, K. Bao, Q. Tao, C. Xu, X. Feng, P. Zhu, T. Cui, Inorg. Chem. 55 (2016) 11140-11146.

[62] S.-Y. Xie, X.-B. Li, W.Q. Tian, N.-K. Chen, X.-L. Zhang, Y. Wang, S. Zhang, H.-B. Sun, Phys. Rev. B 90 (2014) 035447.

[63] Y. Wang, J. Lv, L. Zhu, Y. Ma, Phys. Rev. B 82 (2010) 094116.

[64] Y. Wang, M. Miao, J. Lv, L. Zhu, K. Yin, H. Liu, Y. Ma, J. Chem. Phys. 137 (2012) 224108.

[65] Y. Wang, J. Lv, L. Zhu, Y. Ma, Comput. Phys. Commun. 183 (2012) 2063-2070.

[66] G. Kresse, J. Furthmüller, Phys. Rev. B 54 (1996) 11169-11186.

[67] G. Kresse, J. Furthmuller, Comp. Mater. Sci. 6 (1996) 15-50.

[68] G. Kresse, J. Hafner, Phys. Rev. B 47 (1993) 558-561.

[69] Z. Guo, J. Zhou, C. Si, Z. Sun, Phys. Chem. Chem. Phys. 17 (2015) 15348-15354.

[70] B. Anasori, M.R. Lukatskaya, Y. Gogotsi, Nat. Rev. Mater. 2 (2017) 16098.

[71] B.T. Wang, P. Zhang, H.L. Shi, B. Sun, W.D. Li, Eur. Phys. J. B 74 (2010) 303-308.

[72] S. Otani, Y. Ishizawa, J. Cryst. Growth 140 (1994) 451-453.

[73] H. Klesnar, T.L. Aselage, B. Morosin, G.H. Kwei, J. Alloy. Compd. 241 (1996) 180-186.

[74] H. P. Klesnar, P. Rogl, High Temp. High Press. 22 (1990) 453-457.

[75] L.N. Kugai, Inorg. Mater. 4 (1972) 669-670.

[76] B.-T. Wang, W. Zhang, W.-D. Li, Sci. Adv. Mater. 5 (2013) 1916-1921.

[77] G. Levchenko, A. Lyashchenko, V. Baumer, A. Evdokimova, V. Filippov, Y. Paderno, N. Shitsevalova, J. Solid State Chem. 179 (2006) 2949-2953.

[78] H. Zhang, Y. Li, J. Hou, A. Du, Z. Chen, Nano Lett. 16 (2016) 6124-6129.

[79] Z. Zhang, X. Liu, B.I. Yakobson, W. Guo, J. Am. Chem. Soc. 134 (2012) 19326-19329.

[80] L.M. Yang, V. Bacic, I.A. Popov, A.I. Boldyrev, T. Heine, T. Frauenheim, E. Ganz, J. Am. Chem. Soc. 137 (2015) 2757-2762.

[81] A. Molina-Sánchez, L. Wirtz, Phys. Rev. B 84 (2011) 155413.

[82] H. Liu, A.T. Neal, Z. Zhu, Z. Luo, X. Xu, D. Tománek, P.D. Ye, ACS Nano 8 (2014) 
4033-4041.

[83] K.F. Mak, C. Lee, J. Hone, J. Shan, T.F. Heinz, Phys. Rev. Lett. 105 (2010) 136805.

[84] K. Toyoura, Y. Koyama, A. Kuwabara, F. Oba, I. Tanaka, Phys. Rev. B 78 (2008) 214303.

[85] P. Ganesh, J. Kim, C. Park, M. Yoon, F.A. Reboredo, P.R.C. Kent, J. Chem. Theory Comput. 10 (2014) 5318-5323.

[86] W.-J. Zhang, J. Power Sources 196 (2011) 13-24.

[87] W. Wenhui, Z. Qianfan, C. Yi, W. Enge, J. Phys. Condens. Mat. 22 (2010) 415501.

[88] C.-Y. Chou, H. Kim, G.S. Hwang, J. Phys. Chem. C 115 (2011) 20018-20026.

[89] K. Nakada, A. Ishii, Solid State Commun. 151 (2011) 13-16.

[90] C. Ling, F. Mizuno, Phys. Chem. Chem. Phys. 16 (2014) 10419-10424.

[91] B. Ziebarth, M. Klinsmann, T. Eck1, C. Elsässer, Phys. Rev. B 89 (2014) 174301.

[92] X. Qu, J. Yang, Y. Wang, J. Lv, Z. Chen, Y. Ma, Nanoscale 9 (2017) 17983-17990.

\section{Graphical Abstract:}

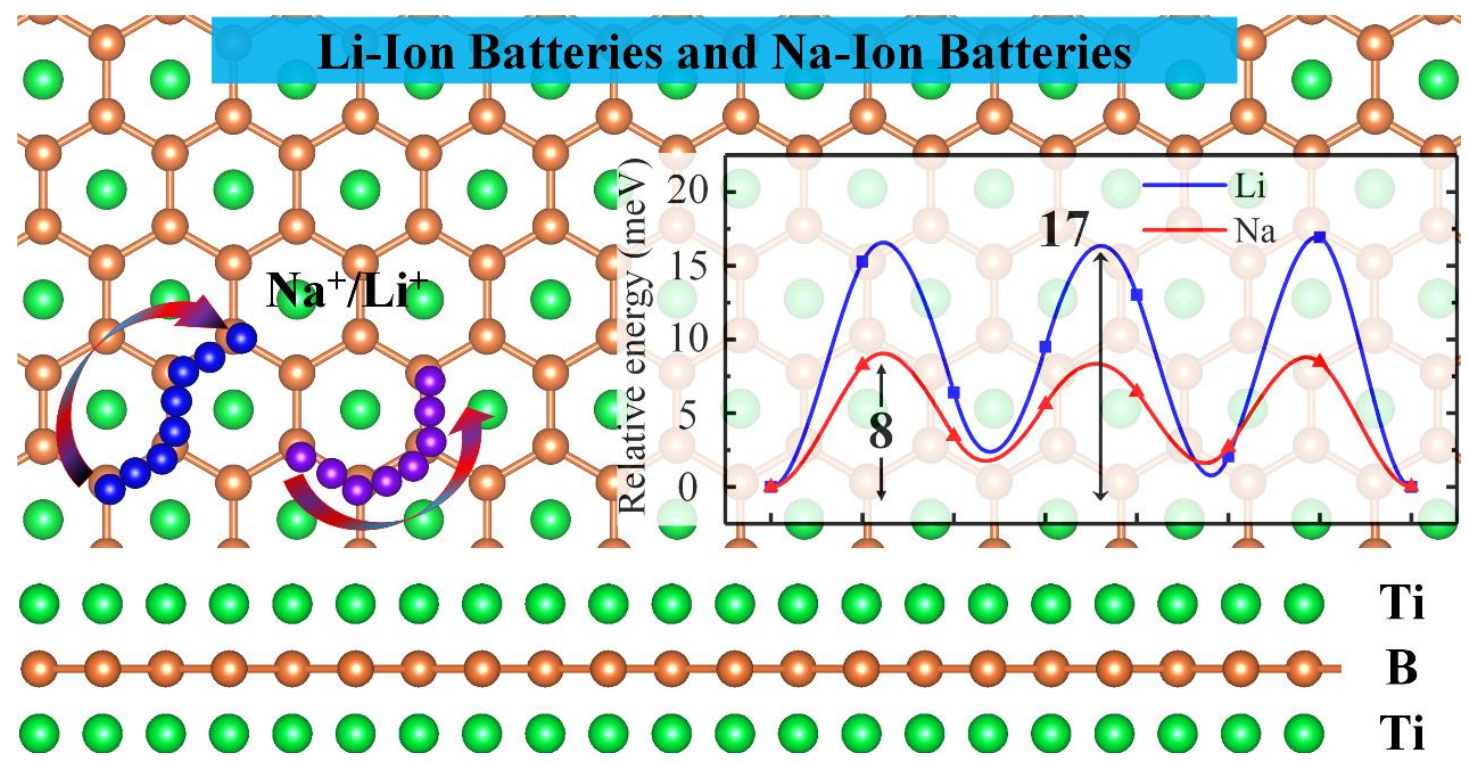

